\title{
Features of Suffering Perceived by Japanese Patients in a Stable Condition: A Text Analysis
}

\author{
Mayumi Uno, Tomomi Tsujimoto, Tomoko Inoue \\ Department of Nursing Science, Graduate School of Medicine, Osaka University, Osaka, Japan \\ Email: unomayu@gmail.com
}

How to cite this paper: Uno, M., Tsujimoto, T. and Inoue, T. (2017) Features of Suffering Perceived by Japanese Patients in a Stable Condition: A Text Analysis. Open Journal of Nursing, 7, 1021-1033. https://doi.org/10.4236/ojn.2017.79074

Received: August 7, 2017

Accepted: September 15, 2017

Published: September 18, 2017

Copyright @ 2017 by authors and Scientific Research Publishing Inc. This work is licensed under the Creative Commons Attribution International License (CC BY 4.0).

http://creativecommons.org/licenses/by/4.0/ (c) (i) Open Access

\begin{abstract}
Objectives: We performed a text analysis of telephone consultation content regarding features of suffering (thoughts that patients cannot express to nurses) perceived by Japanese patients in a stable condition. Methods: Semi-structured interviews were conducted by 8 telephone counselors who listened to patients' suffering. Interview content was recorded verbatim, text was organized, and a text and association analysis was conducted (cluster analysis, bubble plot analysis, and a co-occurrence network analysis). Results: Seventy-two conversations were obtained and analyzed. It was confirmed that suffering as perceived by stable, Japanese patients had consistent concerns such as "lack of inference," "privacy issues," and "nurses' not intervening on patients' behalf." Additionally, expectations of patients when patients are suffering are extremely diverse and were not characterized by specific tendencies. Conclusions: Emotions have a complicated influence in the context of Japanese patients' suffering. It is necessary to consider the cultural background of expression in Japan to treat patients' suffering.
\end{abstract}

\section{Keywords}

Nurse-Patient Relationship, Emotion, Suffering, Text Analysis, Culture

\section{Research Background and Significance}

\subsection{Patient Satisfaction and Nursing Quality}

Patient satisfaction in facilities such as hospitals is related to the quality of nursing care and should be emphasized [1] [2]. Sustained high patient satisfaction is essential for the survival of medical institutions; when patients are unsatisfied, they do not recommend that medical institution to family members, friends, or colleagues [3] [4] [5] [6]. In other words, nurses play a vital role in influencing patients' satisfaction within the health care team [7]. Additionally, nursing is 
part of a comprehensive medical system and the process and structural factors influence patients' satisfaction with nursing care [8]-[15].

\subsection{Nurse-Patient Relationship}

Nurse-patient communication is said to support patient-centered care, evidence-based practice, and the application of quality improvement [16] [17] [18]. Interpersonal relationships based on the nurse-patient relationship are important for nurses when evaluating, planning, and intervening with patients [19]. As Peplau [20] noted in her nurse-patient relationship theory that, nursing is an educational means and a developed strength that promotes the advancement of nursing, and mutual relationships are key. To favorably maintain mutual relationships, it is important to understand patient suffering and nurses' empathic involvement.

\subsection{Suffering Arising from Nurse-Patient Conflict}

Bissell and colleagues [21] suggest maintaining a positive relationship between patients and medical staff means "to cultivate a mutual relationship and distinguish understanding" and states that conflict will occur if mutual relationships cannot be smoothly maintained. Robbins [22] defined conflict as "a process that begins when one party recognizes that the other party has adversely affected or is about to affect important matters for him/her."

In a series of studies focusing on conflicts between nurses and patients under circumstances where patients' mind-body condition is treated as "stable" (i.e., "not tense," "not in a terminal stage," and "no mental illness" [23] [24] [25] [26], there was an underlying sense that patients were unable to express themselves to nurses. In these studies, suffering was understood as the state of a patient who could not convey his/her thoughts on medical treatment. In other words, suffering occurs when patients cannot express themselves to nurses. To effectively understand suffering, we used interviews rather than scale measurements. Analyzing the contents of interviews was deemed suitable for this study.

\subsection{Purpose}

We conducted a text analysis of telephone consultation content regarding features of suffering (i.e., thoughts that patients cannot express to nurses) perceived by patients in a stable condition.

\section{Methods}

\subsection{Participants}

Among the 20 telephone consultants, participants comprised eight telephone counselors belonging to a non-profit organization based in Osaka, Japan.

\subsection{Data Collection}

We determined that it would be difficult to interview patients directly and obtain 
their real feelings; therefore, we utilized consultation content with telephone counselors.

Semi-structured interviews with telephone counselors were conducted (November 2013-February 2014). We focused on conflict with nurses as events as examples of suffering. Interviews referenced the framework of Robbins' [22] conflict process and primarily comprised the following: 1) Under what situations and conditions did conflict between a nurse and patient arise? 2) What were the underlying factors in the conflict? 3) When conflict arose, what response did the patient desire from the nurse?

Interviews were held in a quiet, private room for approximately 40 minutes. Interview content was recorded with an IC recorder with permission from the participants and all content was recorded verbatim. The data from 40 individuals from prior telephone consultations [27] was also added to the analysis. This additional content was received after a telephone consult with the non-profit organization that acquired the data through interviews. In other words, we added data that was obtained in a comparable way as the interviews in this study. The interviews with the eight counselors and additional 40 examples that were added resulted in 72 episodes. Saturation was observed in the analysis process, resulting in sufficient data.

\subsection{Ethical Considerations}

We explained that data obtained from this study would not be used for any purpose other than research, that individuals would not be specified, and that data would be strictly managed and destroyed completely after study completion. Cooperation was voluntary and there was no disadvantage to not providing consent, which would also not impact the evaluation of the telephone consultation. This study was conducted with approval from the ethics review committee of our affiliated university.

\subsection{Analysis Process}

IBM SPSS Text Analytics for Surveys was used for text analysis for Japan and a morphological analysis of sentences was performed. After carefully reading the text, researchers organized the language expression variations containing the same meaning (e.g., the meaning of utterances such as "nurse," "nurses," "staff," "she/he," etc. were unified under "nurse"), which made the morphological analysis reliable. Next, to perform a statistical analysis, words were given a number value based on the number of occurrences. The text-mining analysis software $\mathrm{R}$, $\mathrm{KH}$ coder was used and relationships and features among the text that appeared were analyzed through cluster, co-occurrence network, and bubble plot analyses.

\section{Results}

\subsection{Participants' Attributes}

Telephone counselors were all aged 65 years or older, female, and had mean ex- 
perience of 6.7 years (standard deviation $=4.12$ years) in telephone consulting. Obtained data consisted of 32 conversations; therefore, after adding the 40 conversations from a prior study, total data comprised 72 conversations. After confirming that these were consistent with this study's purpose, all were targeted for analysis.

\subsection{Analysis Methods and Results}

In the hierarchical cluster analysis, words surrounded by squares are characteristically few. Particularly, words low in the hierarchy and in a low position are characteristically connected.

In the bubble plot analysis, the same color indicates the same group. Circle size represents occurrence frequency. In this graph, the intersection of dimension 1 and dimension $2(0,0)$ is the center and the distance from the center becomes a characteristic.

In the co-occurrence network analysis, items with a high occurrence are shown in order of pink, white, and blue (from darker to lighter colors). Items connected by lines have a co-occurrence relationship and thicker lines indicate deeper relationships. Particularly, words connected in isolated positions from the whole are understood as a characteristic.

\subsection{Features of Suffering Perceived by Japanese Patients in Stable Conditions}

Hierarchical cluster, bubble plot, and co-occurrence network analyses results revealed the following characteristics. The important results in the following figure are indicated with a star and a circle

Features involving setting and situations included the following (Figures 1-3): "lack of inference" and "timing problems." An example of a timing problem is "the nurse does not respond to calls in a timely fashion."

Latent factors when patients perceived suffering revealed the following features (Figures 4-6): "privacy issues" (e.g., personal information) and "nurses' not intervening on patients' behalf." (e.g., nurses' do not help keep rooms quiet).

Japanese patients' expectations of nurses when suffering in a stable condition revealed no particularly strong relationships (Figures 7-9). In other words, results showed that the words were extremely diverse.

Because there are no features, stars and circles are not included in the figures.

\section{Discussion}

Analysis revealed several situations that were associated with patients' suffering. These are described below.

\subsection{Setting and Situational Features}

\subsubsection{Lack of Inference}

Original text case: "Even if the patient reached the scheduled time for discharge, he/she was unable to be discharged and received no explanation from the nurse 


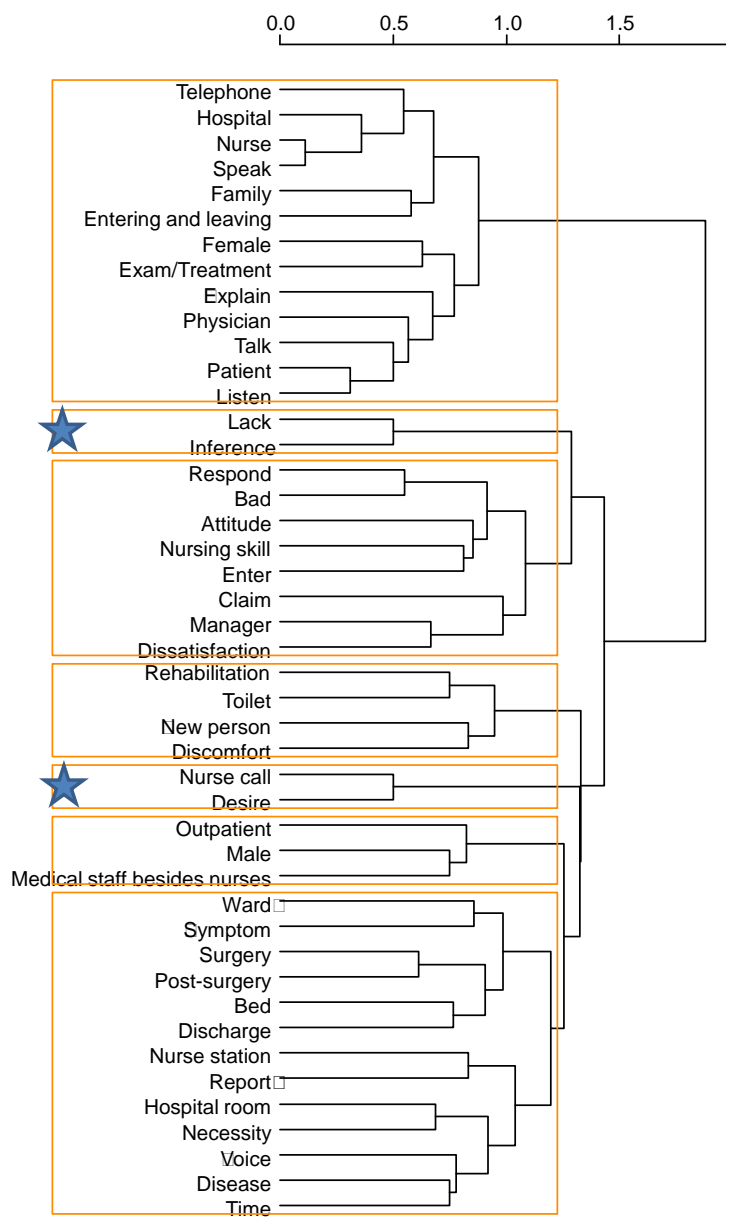

Figure 1. Hierarchical cluster of settings and situations of suffering perceived by patients in a stable condition.

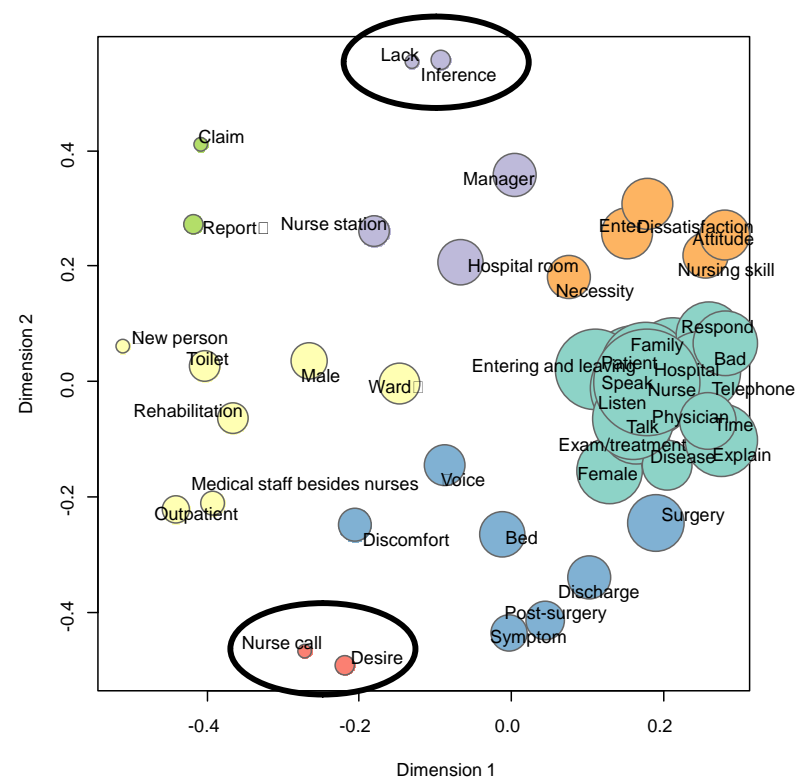

Figure 2. Bubble plot of settings and situations of suffering perceived by patients in a stable condition. 


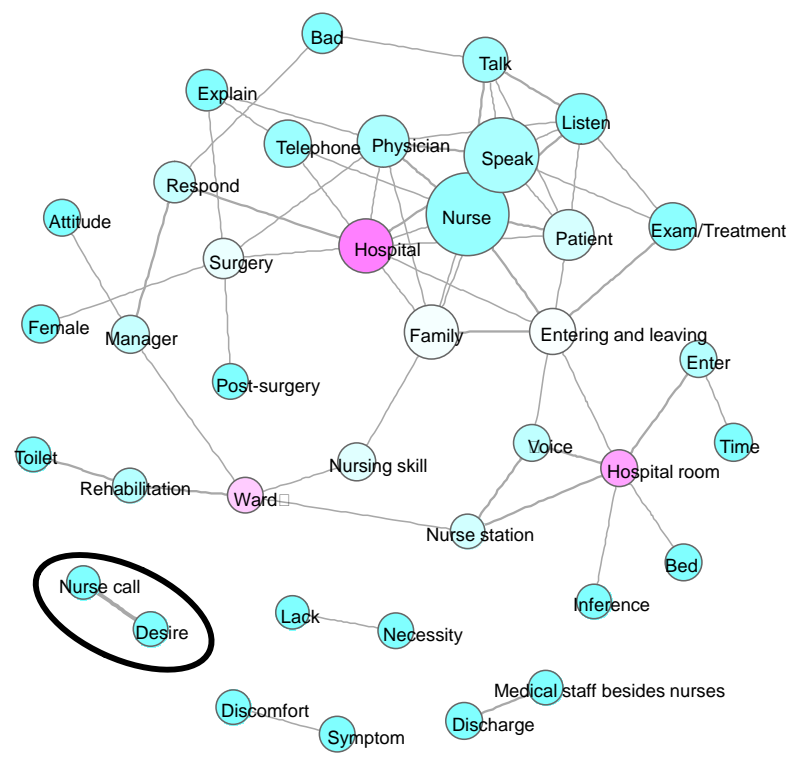

Figure 3. Co-occurrence network of settings and situations of suffering perceived by patients in a stable condition.

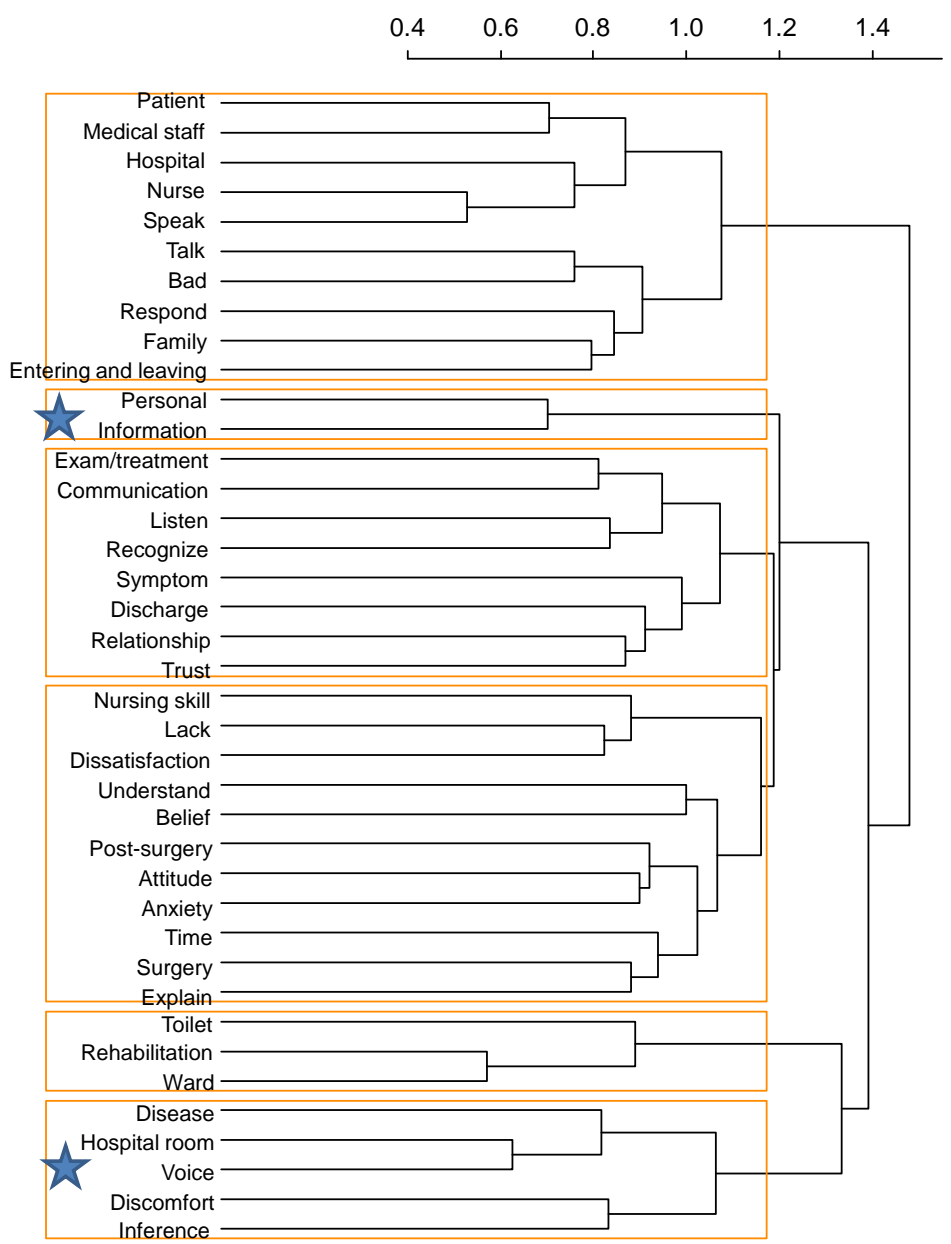

Figure 4. Hierarchical cluster of latent factors in suffering perceived by patients in a stable condition. 


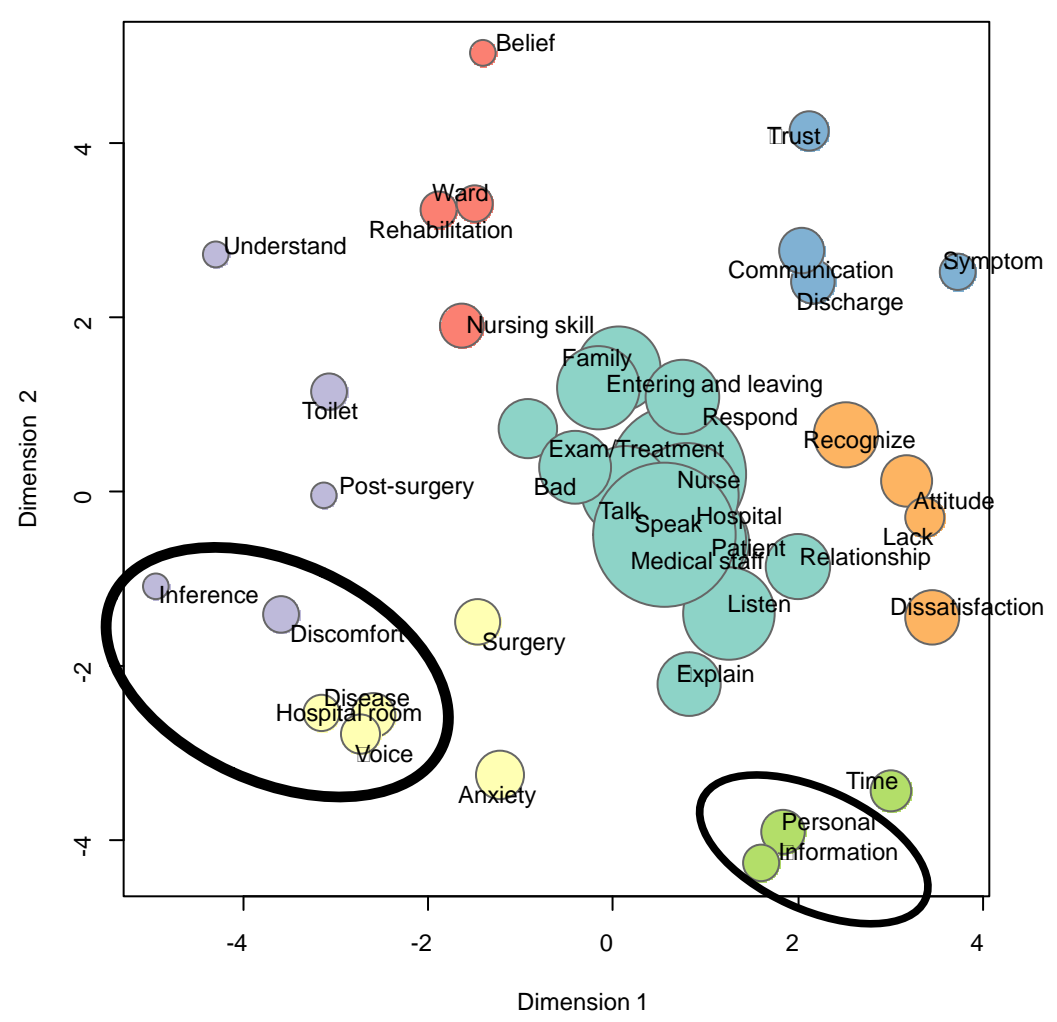

Figure 5. Bubble plot of latent factors in suffering perceived by patients in a stable condition

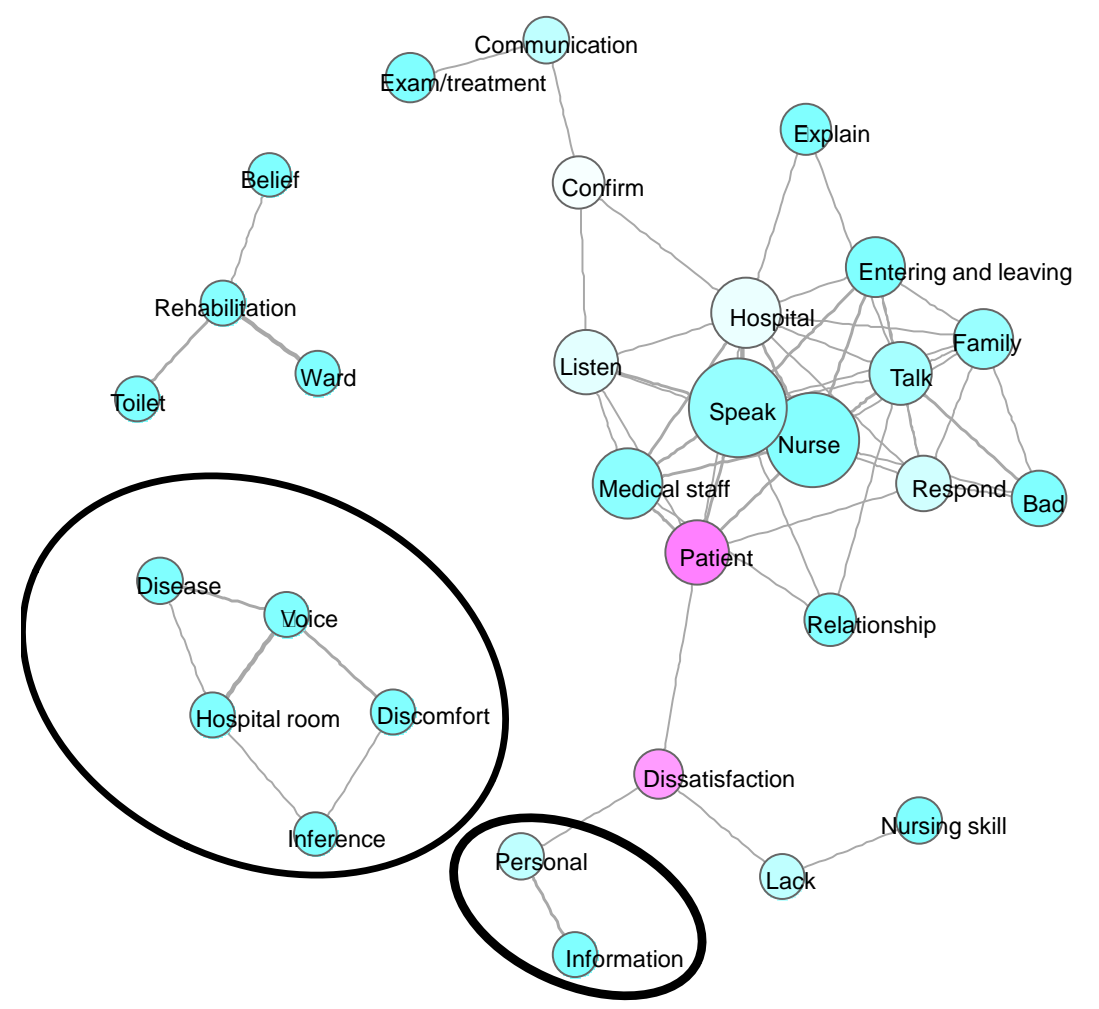

Figure 6. Co-occurrence network of latent factors in suffering perceived by patients in a stable condition. 


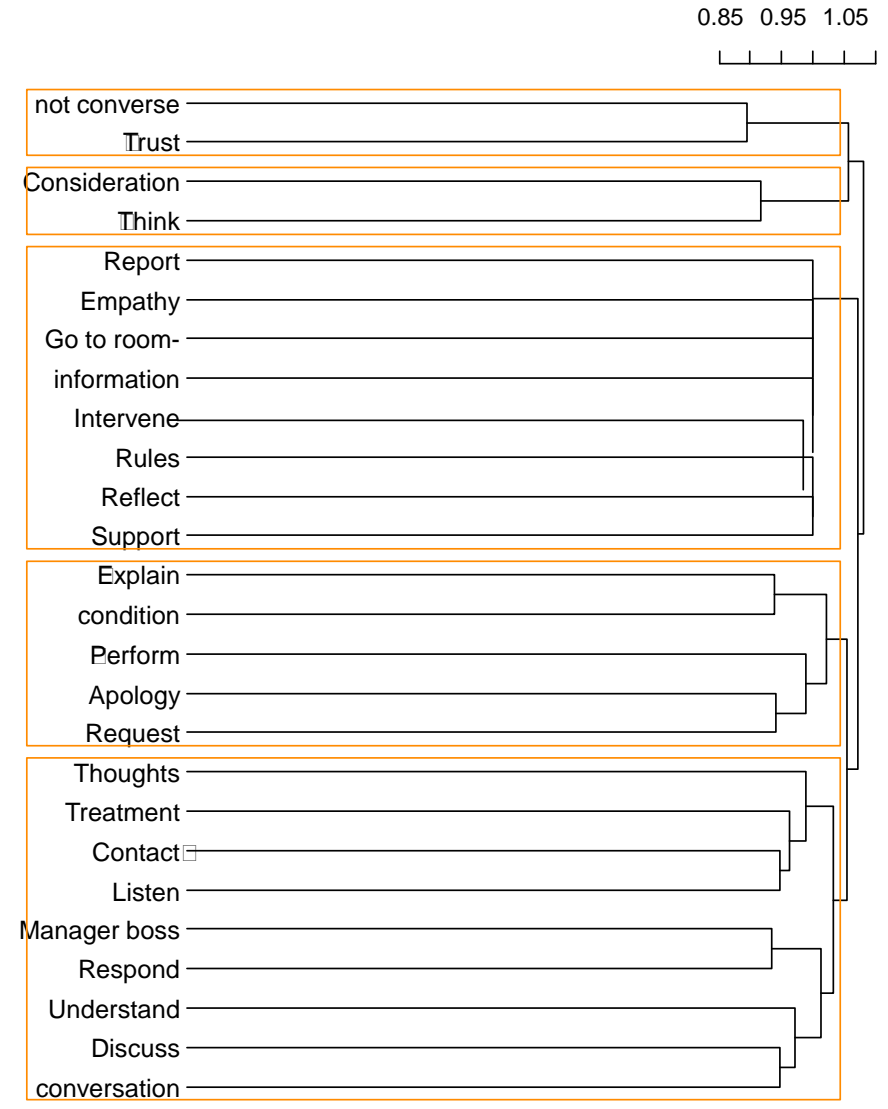

Figure 7. Hierarchical cluster of Japanese patients' expectations of nurses when suffering in a stable condition.

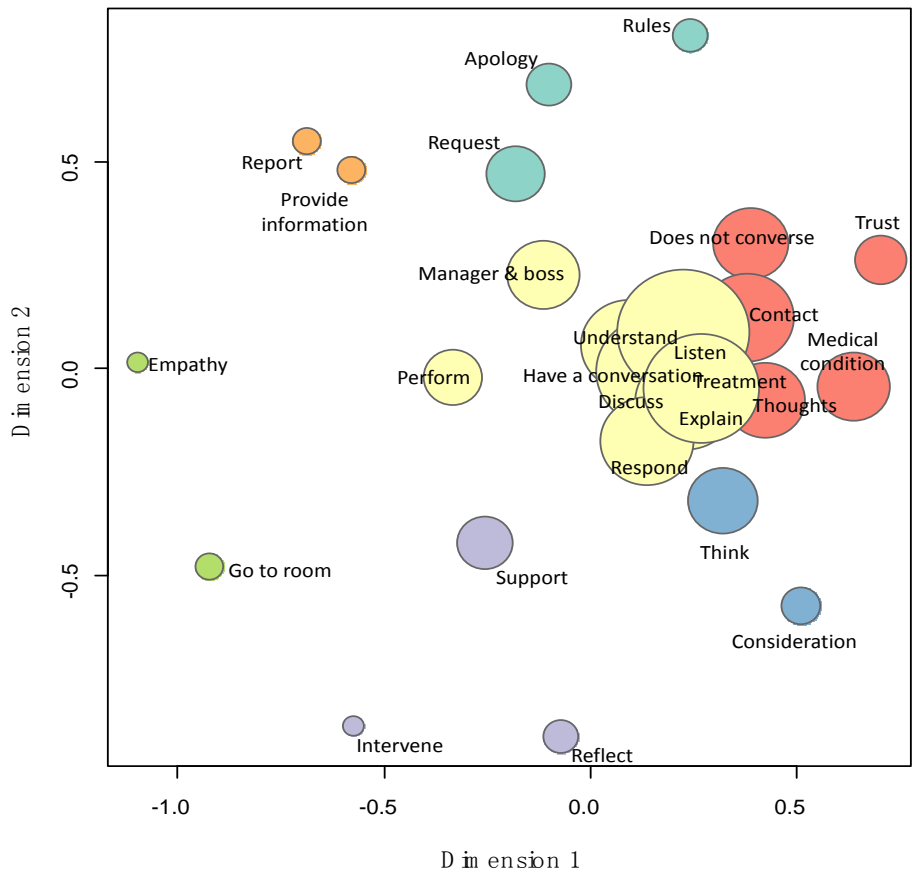

Figure 8. Bubble plot of Japanese patients' expectations of nurses when suffering in a stable condition. 


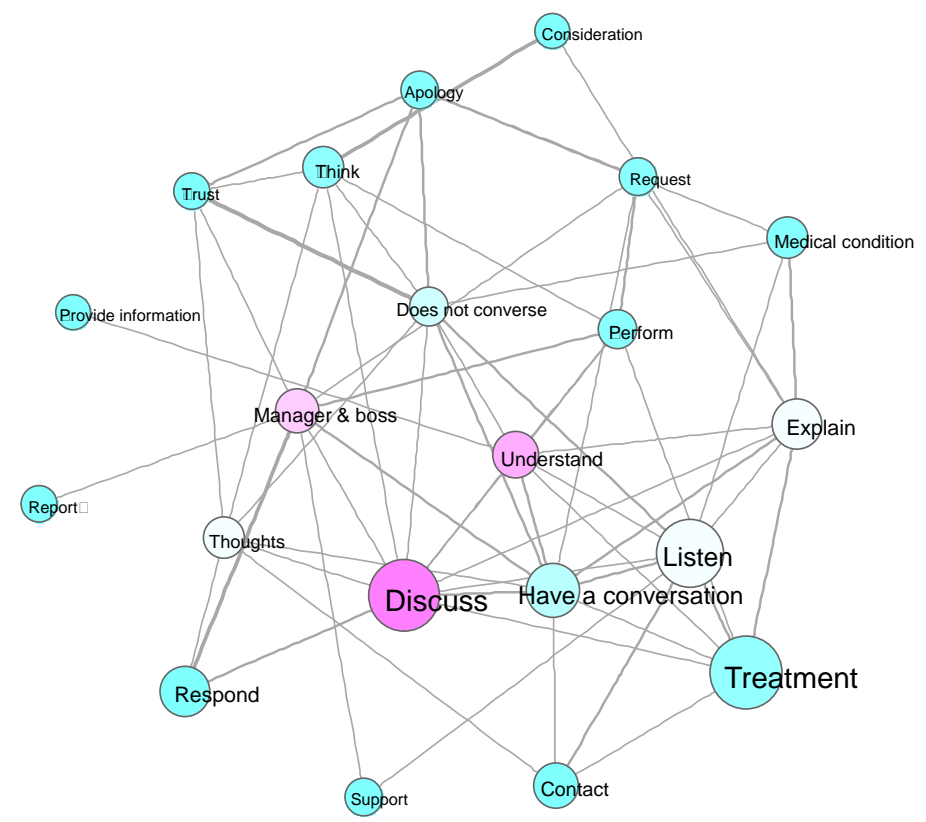

Figure 9. Co-occurrence network of Japanese patients' expectations of nurses when suffering in a stable condition.

\section{regarding this."}

As an interpretation of this, the patient is preparing for the next scheduled discharge time. However, the nurse does not infer the patient's irritated affect and he/she provides no response (explanation). The nurse is busy performing care for other patients and recognizes that other patients are a priority. Therefore, the patient suffers while waiting patiently without declaring his/her thoughts of the irritation. The patient's irritation becomes the focus. Affect is a generic name indicating various feelings aperson experiences; it is closely related to emotion and mood [28] and clearly indicates how a person feels [29]. Although the patient is irritated (affect), he/she cannot clearly and logically convey this to the nurse. In other words, when a situation cannot be understood objectively, the affect of the involved parties increases. Affect is subjective, and it has been suggested that it is impossible to adequately convey the properties of affect in language [30].

\subsubsection{Timing Problems}

Original text case: "The nurse did not notice that a nurse call was made from the toilet and the patient was left waiting in the toilet for quite a long time. There was no apology for this that satisfied the patient."

As an interpretation of this, the patient's experience of being kept waiting in the toilet caused fear. However, it was a busy period for the nurse and the nurse recognized that the response was slightly delayed. Consequently, there is a gap between the nurse and patient regarding time. When the patient perceives and inappropriate gap, he/she feels suffering. There is an existing gap between nurses who are actively busy throughout the day and patients whose activity level is de- 
creasing due to treatment; this also influences how events are understood. When taking an action-research approach, the process of learning through living experience includes the potential to reduce the gap between theory and practice [31] [32] [33]. By having a real sensation by entering the lives of others, one can move toward a solution. However, it is suggested that if it is impractical to enter a patient's life, nurses must use their imagination.

\subsection{Latent Factors in Suffering}

\subsubsection{Privacy Issues}

Original text case: "I cannot leave my bed and when I mentioned that there was something I wanted to consult with the nurse about, the nurse said in a voice loud enough for the other patients and visitors in the room to hear: 'What's the matter? Please go ahead and tell me, whatever it is.' The nurse didn't consider that I wanted to speak privately."

As an interpretation of this, although the patient was asked by the nurse, it was without consideration, and the patient endured feeling discomfort.

\subsubsection{Nurses' Not Intervening on Patients' Behalf}

Original text case: "In situations where my physical strength is extremely depleted, such as fever, etc., voices of other visitors in the same room are very noisy. I want the nurse to notice this and warn them (on my behalf)."

Although the patient's condition was stable, he/she had a fever. Therefore, he/she is very uncomfortable when it is too noisy. In this case, the patient was concerned that if he/she warns the visitors, it will harm his/her relationship with the other patients in the room; therefore, he/she would like the nurse, who is neutral, to warn them. The patient recognizes that these warnings are the nurse's responsibility. If this is not enacted, it becomes a latent factor in the patient's suffering.

Therefore, this factor is related to affect control such as suppression; concentration; and retention of a condition, urge, or emotion [34]. Although affect control is a socially necessary skill, it is thought to lead to suffering if its exceeds the patient's personal range of control. Suffering is a personal perception or experience; since humans perceive the experience of suffering in unique ways [35], it may be difficult for another person (in this case the nurse) to notice. Therefore, a "lack of the nurse's awareness" became a latent factor in the patient's perceived suffering.

\subsection{Japanese Patients' Expectations of Nurses}

Since no particularly strong relationships were shown, it is believed that patients' expectations are thought to be very diverse and without patterns. For patients to receive high-quality care, it is extremely important for nurses to understand patient suffering [36] and Millar [37] points out that communication is a core element of this. In other words, a nurse is required to sense the patients' expectations from communication one who is unable to do so is thought to cause pa- 
tient suffering. In contrast, it is also necessary to determine patients' feelings through their non-verbal communication.

\subsection{Cultural Factors}

In Japan, individuals are taught to coexist and not harm others. They are also taught to avoid expressing affect such as personal thoughts and emotions. Expressing one's thoughts and emotions indirectly rather than directly is an art and uses a variety of expressive methods. Consequently, there is an expectation that one wants to and wants other to infer truth. That is, words such as "attentiveness" and "concern" that express Japanese spirit [38] are at the foundation and the space between people that creates a positive atmosphere (in Japanese, awai) is a characteristic of Japanese communication. However, the existing problem is that Japanese nurses are following Western teaching and communication. These cultural factors are not applicable to Japanese patients, and nurses are not perceiving their suffering effectively.

\subsection{Clinical Contributions}

Patients' in stable conditions have their thoughts easily overlooked. However, by understanding the characteristics of patients' perceived suffering and using basic communication skills, the nurse-patient relationships can be improved and high-quality nursing care can be provided. Communication that reaffirms diverse cultural backgrounds is necessary.

\subsection{Study Limitations and Future Prospects}

Rather than separately examining the perceptions of nurses or patients, it is necessary to concurrently verify conflicts and other situations that arise between nurses and patients and to conceptualize both nurses' and patients' perception of suffering.

\section{Conclusion}

Features of suffering perceived by Japanese patients in a stable condition included factors such as "lack of inference," "privacy issues," and "nurses' not intervening on patients' behalf." These were shown through a text analysis, which suggested that emotion has a complicated influence. Moreover, the Japanese culture of expression influences patients' suffering; however, it seems that Japanese nurses tend to forget this.

\section{Acknowledgements}

We extended our heartfelt appreciation to all those who kindly assisted with this study. There are no conflicts of interest to declare.

\section{References}

[1] Otani, K. and Kurz, R.S. (2004) The Impact of Nursing Care and Other Healthcare 
Attributes on Hospitalized Patient Satisfaction and Behavioural Intentions. Journal of Healthcare Management, 49, 181-196.

[2] Sharma, S.K. and Kamra, P.K. (2013) Patient Satisfaction with Nursing Care in Public and Private Hospitals. Nursing and Midwifery Research Journal, 9, 130-141.

[3] Ellis-Jacobs, K.A. (2011) A Quantitative Correlational Study on the Impact of Patient Satisfaction on a Rural Hospital. The Internet Journal of Allied Health Sciences and Practice, 9. http://ijahsp.nova.edu/articles/Vol9Num4/pdf/ellis-jacobs.pdf

[4] Lee, M.A. and Yom, Y.H. (2007) A Comparative Study of Patients' and Nurses' Perceptions of the Quality of Nursing Services, Satisfaction and Intent to Revisit the Hospital: A Questionnaire Survey. International Journal of Nursing Studies, 44, 545-555. https://doi.org/10.1016/j.ijnurstu.2006.03.006

[5] Shirley, E.D. and Sanders, J.O. (2013) Patient Satisfaction: Implications and Predictors of Success. The Journal of Bone and Joint Surgery. American Volume, 95, e69-1-4.

[6] Ting, C.Y. and Yu, T.K. (2010) Modeling Patient Perceptions of Service Recovery: The Effects of Perceived Fairness on Health Center Repatronage. Social Behavior and Personality, 38, 395-403. https://doi.org/10.2224/sbp.2010.38.3.395

[7] Dzomeku, V.M., Ba-Etilayoo, A., Perekuu, T. and Mantey, R.E. (2013) In-Patient Satisfaction with Nursing Care: A Case Study at Kwame Nkrumah University of Science and Technology Hospital. International Journal of Medical Research and Health Sciences, 2, 19-24.

[8] Donabedian, A. (1992) The Role of Outcomes in Quality Assessment and Assurance. QRB-Quality Review Bulletin, 11, 356-360. https://doi.org/10.1016/S0097-5990(16)30560-7

[9] Nelson, E.C., Mohr, J.J., Batalden, P.B. and Plume, S.K. (1996) Improving Health Care, Part 1: The Clinical Value Compass. The Joint Commission Journal on Quality Improvement, 22, 243-258. https://doi.org/10.1016/S1070-3241(16)30228-0

[10] Irvine, D., Sidani, S. and Mc Gillis, L.H. (1998) Linking Outcomes to Nurses' Roles in Health Care. Nursing Economic, 2, 58-64.

[11] Duffy, J.R. and Hoskins, L.M. (2003) The Quality-Caring Model. Advances in Nursing Science, 26, 77-78. https://doi.org/10.1097/00012272-200301000-00010

[12] Korniewicz, D.M. and Duffy, J. (2008) Essential Concepts for Staff Nurses: The Outcomes Imperative. American Nurses Association, Continuing Education.

[13] Mark, B., Salyer, J. and Wan, T.T.H. (2003) Professional Nursing Practice: Impact on Organizational and Patient Outcomes. Journal of Nursing Administration, 22, 224-234. https://doi.org/10.1097/00005110-200304000-00008

[14] Yen, M. (2004) A Model for Testing the Relationship of Nursing Care and Patient Outcomes. Nursing Economic, 22, 75-80.

[15] Tzeng, H.M. and Yin, C.Y. (2008) Patient Satisfaction versus Quality. Nursing Ethics, 15, 121-124. https://doi.org/10.1177/0969733007080210

[16] Greiner, A.C. and Knebel, E. (2004) Health Professions Education: A Bridge to Quality. Journal for Healthcare Quality, 26, 54. https://doi.org/10.1111/j.1945-1474.2004.tb00473.x

[17] Institute of Medicine, Committee on Quality of Health Care in America (2001) Crossing the Quality Chasm: A New Health System for the 21st Century. Executive Summary. http://books.nap.edu/catalog/10027.html

[18] World Health Organization (2008) Communication during Patient Handovers. Patient Safe Solutions, 1, 1-4. 
[19] Peterson, S.J. (2009) Interpersonal Relations. In: Peterson, S.J. and Bredow, T.S., Eds., Middle Range Theories. Application to Nursing Research, Lippincott Williams \& Wilkins, Philadelphia, 202-230.

[20] Peplau, H.E. (1991) Interpersonal Relations in Nursing: A Conceptual Frame of Reference for Psychodynamic Nursing. Springer, New York.

[21] Bissell, P., May, C.R. and Noyce, P.R. (2004) From Compliance to Concordance: Barriers to Accomplishing a Re-Framed Model of Health Care Interactions. Social Science \& Medicine, 58, 851-862.

[22] Robbins, S.P. (2009) Essentials of Organizational Behavior. 8th Edition, Pearson Education, Inc., Prentice Hall, Diamond. (In Japanese)

[23] Uno, M., Tsujimoto, T. and Inoue, T. (2014) Effect of Conflicts in Patient-Nurse Relations. Nursing Journal Osaka University, 20, 47-53. (In Japanese)

[24] Uno, M. (2015) A Study Using SERVQUAL to Evaluate Trends in Patient Expectations when Conflict Arises. Journal of Yamato University, 1, 173-179.

[25] Uno, M., Ikuta, S. and Okamoto, M. (2016) Aspects of Avoidance of Conflict between Nurses and Patients, According to Gold Nurses (or Expert Nurses): A Program for Raising the Quality of Nursing. Journal of Yamato University, 2, 91-97.

[26] Uno, M., Tsujimoto, T. and Inoue, T. (2017) Perceptions of Nurses in Japan toward Their Patients' Expectations of Care: A Qualitative Study. International Journal of Nursing Sciences, 4, 58-62.

[27] Yamaguchi, I. (2011) Anna Nurse, Konna Nurse. Clinical Study, 19-30. (In Japanese)

[28] George, J.M. (1991) State or Trait: Effects of Positive Mood on Prosocial Behaviors at Work. Journal of Applied Psychology, 76, 299-307. https://doi.org/10.1037/0021-9010.76.2.299

[29] Langer, S. (1964) Philosophical Sketches. The New American Library of World Literature, New York.

[30] Rogers, M.E. (1970) An Introduction to the Theoretical Basis of Nursing. Nursing Research, 19, 541. https://doi.org/10.1097/00006199-197011000-00012

[31] Webb, C. (1989) Action Research: Philosophy, Methods and Personal Experiences. Journal of Advanced Nursing, 25, 485-491. https://doi.org/10.1111/j.1365-2648.1989.tb01548.x

[32] Titchen, A. and Binnie, A. (1994) Action Research: A Strategy for Theory Generation and Testing. International Journal of Nursing Studies, 31, 1-12.

[33] Simmons, S. (1995) From Paradigm to Method in Interpretive Action Research. Journal of Advanced Nursing, 21, 837-844. https://doi.org/10.1046/j.1365-2648.1995.21050837.x

[34] Wegner, D.M. (1994) Ironic Process of Mental Control. Psychological Review, 101, 34-52. https://doi.org/10.1037/0033-295X.101.1.34

[35] Travelbee, J. (1971) Interpersonal Aspects of Nursing. Nursing Management, 1, 44. https://doi.org/10.1097/00006247-197112000-00009

[36] Bégat, I.B. and Severinsson, E.I. (2001) Nurses' Reflections on Episodes Occurring during Their Provision of Care-An Interview Study. International Journal of Nursing Studies, 38, 71-77.

[37] Millar, B., Maggs, C., Warner, V. and Whale, Z. (1996) Creating Consensus about Nursing Outcomes. II. Nursing Outcomes as Agreed by Patients, Nurses and Other Professionals. Journal of Clinical Nursing, 5, 263-267.

[38] Haga, Y. (2013) Nihonjin-rasisa-no-hakken. Taisyukansyoten, Tokyo. (In Japanese) 
Submit or recommend next manuscript to SCIRP and we will provide best service for you:

Accepting pre-submission inquiries through Email, Facebook, LinkedIn, Twitter, etc. A wide selection of journals (inclusive of 9 subjects, more than 200 journals)

Providing 24-hour high-quality service

User-friendly online submission system

Fair and swift peer-review system

Efficient typesetting and proofreading procedure

Display of the result of downloads and visits, as well as the number of cited articles Maximum dissemination of your research work

Submit your manuscript at: http://papersubmission.scirp.org/

Or contact ojn@scirp.org 